\title{
Direito à memória das comunidades tradicionais: organização de acervo nos terreiros de candomblé de Salvador, Bahia
}

\author{
Andréa Carvalho Oliveira \\ Coordenadora do Centro de Documentação Koinonia \\ Presença Ecumênica e Serviço. Coordenadora das oficinas de \\ direito à memória em comunidades de terreiros de candomblé, \\ Salvador-BA. Coordenadora do Portal Ecumênico Latino \\ Americano e Caribe. \\ E-mail: andreacoliveira@hotmail.com
}

\section{Resumo}

Este artigo conta a experiência da instituição Koinonia Presença Ecumênica e Serviço na realização de Oficinas de Direito à Memória, com ênfase na organização de acervos com comunidades tradicionais de terreiros de candomblé de diferentes nações, localizados em Salvador, Bahia.

\section{Palavras-chave}

Memória. Identidade. Cultura. Terreiro de Candomblé Bahia.

Right to the memory of traditional communities: organization of collections in Candomblé sites, in Salvador, Bahia

\begin{abstract}
This article recounts to the experience of the institution Koinonia Presença Ecumênica e Serviço in carrying out Workshops on Right to the Memory, with emphasis on the organization of collections with traditional communities of candomblé sites from different nations, situated in Salvador, Bahia.
\end{abstract}

Keywords

Memory. Identity. Culture. Fetichism. Candomblé sites Bahia.

\section{INTRODUÇÃO}

Koinonia - Presença Ecumênica e Serviço fica localizada no bairro da Glória, no Rio de Janeiro, em uma casa de dois andares onde trabalham 28 pessoas, divididos em funcionários, colaboradores e associados.

É uma instituição ecumênica ${ }^{1}$ que presta serviços a grupos histórica e culturalmente vulneráveis e em processo de emancipação social e política, promovendo o movimento ecumênico e seus valores libertários.

No epicentro das ações de incidência pública estão organizações ecumênicas participantes no Fórum Ecumênico Brasil e agências ecumênicas internacionais de cooperação para o desenvolvimento (AEicd) que, articuladas com e pela Koinonia, desenvolvem ações de comunicação e informação, de diálogo com organismos de Estado e multilaterais e de defesa de direitos econômicos, sociais e culturais como estratégia de combate estrutural à pobreza.

Quanto ao respaldo financeiro, as principais instituições que apoiam as ações de Koinonia são as agências ecumênicas de cooperação internacional que têm acompanhado a organização ao longo dos anos.

Dentro deste contexto, a Koinonia desenvolve cinco programas:

\section{Trabalhadores Rurais e Direitos (TRD)}

Este programa é uma resposta às violações de direitos dos camponeses no Brasil tanto em relação à questão agrária quanto ao modelo de desenvolvimento agrícola, impróprio para a agricultura familiar.

\footnotetext{
${ }^{1}$ Disponível em: www.koinonia.org.br. Acesso em: 16 abr. 09.
} 
Um dos setores camponeses mais afetados por essas questões é a juventude rural, que enfrenta, entre outros, os seguintes problemas: preconceito social que afeta as identidades rurais juvenis; dificuldades de acesso à terra e a políticas de crédito agrícola; e o desafio de construir um protagonismo juvenil em vista de um desenvolvimento rural sustentável.

\section{Ecumenismo, Diálogo e Formação (EDF)}

É uma resposta às demandas de compreensão e compromisso com o campo religioso e ecumênico por parte de diferentes atores da sociedade civil.

Portanto, nos planos de formação dos atores sociais em busca de uma sociedade democrática, ressaltamse as necessidades de convivência com a diversidade (contra toda intolerância) e de compreensão das relações entre a ação sociocultural e as comunidades religiosas.

\section{Saúde e Direitos (SeD)}

O programa Saúde e Direitos tem três objetivos principais: realizar ações educativas sobre saúde e direitos nas diversas comunidades; contribuir para a superação da estigmatização e discriminação de pessoas que vivem ou convivem com HIV/Aids; e incentivar e apoiar lideranças locais das comunidades a desenvolverem atividades relacionadas com os temas HIV/Aids, saúde, educação sexual, direitos sexuais e reprodutivos e relações de gênero.

\section{Redes Ecumênicas e da Sociedade Civil (Resc)}

O contexto mundial tem levado iniciativas proativas da sociedade civil ao enfrentamento dos temas críticos das desigualdades, da paz, da saúde, da sustentabilidade ambiental, entre outros. Campanhas e movimentos têm sensibilizado diferentes setores sociais, cujas respostas articulam diferentes redes de lobby e advocacy, entre elas as iniciativas do movimento ecumênico.

O programa Redes Ecumênicas e da Sociedade Civil busca sistematizar e contribuir para melhor conexão entre as mobilizações ecumênicas internacionais e questões nacionais; maior interação entre iniciativas ecumênicas e outras da sociedade civil; melhor coordenação das diferentes inserções da Koinonia em redes e temas no Brasil, conectando-as com mobilizações nacionais e internacionais.

\section{Territórios Negros (Egbé)}

Egbe $e^{2}$ vem do ioruba, significa nesta língua a sociedade e o lugar onde ela se reproduz. O foco do Programa são os terreiros de candomblé e as comunidades remanescentes de quilombos. Os terreiros são espaços comunitários, onde vivem famílias que configuram uma forma "negra" de ocupar as cidades em meio à especulação imobiliária e ao crescimento desordenado. As comunidades quilombolas também possuem modos tradicionais de ocupação e são hoje um capítulo novo da luta pela terra no país. Sem perder de vista que, cada vez mais, são identificados de um lado quilombos urbanos e, de outro, terreiros de candomblé que se perpetuam no meio rural.

Este relato conta a experiência dessa instituição ao realizar oficinas de organização de acervos em comunidades tradicionais de terreiros de candomblé de diferentes nações, localizados em Salvador, Bahia.

\section{SETOR DOCUMENTAÇÃO: ONDE TUDO COMEÇOU}

O trabalho do setor de documentação da Koinonia visa a fortalecer as temáticas específicas dos programas e projetos da instituição com o processo de aquisição, recuperação, organização e disseminação de livros, periódicos e multimeios. Facilitando o acesso, o uso e a propagação do seu acervo, contribui para geração de novos conhecimentos.

Trabalho na Koinonia desde 2004, e após um ano de adaptação nas atividades organizadas pela instituição, recebo convite para planejar juntamente com o diretor executivo, Rafael Soares de Oliveira, a iniciativa de ministrar oficinas de organização de

${ }^{2}$ Disponível em: www.koinonia.org.br. Acesso em: 16 abr. 09. 
acervos. Até esse ponto nada de inovador, mas realizá-las em terreiros de candomblé, isso sim, seria inédito. Ainda mais que esses terreiros, localizados em Salvador, seriam agentes atuantes nessa atividade e responsáveis pela continuidade dessa ação.

A questão cultural sempre foi um grande patrimônio das comunidades negras tradicionais. Além disso, elementos da cultura e da tradição desses grupos estão presentes nas práticas cotidianas de nossa população. Entretanto, dentro das comunidades, muitas práticas culturais se perderam ou estão se perdendo.

Para Costa (2010), o registro da produção cultural de um povo é a possibilidade mais poderosa para oferecer informações sobre seu desenvolvimento, rever o passado e poder reinventar o futuro através da descoberta de atos e novos conhecimentos.

Para a Koinonia, a formação do público que estabelece alianças (população negra organizada em comunidades urbanas e rurais, trabalhadores rurais, agentes de solidariedade com pessoas que vivem com HIV/Aids, e lideranças intermediárias das igrejas) apresenta-se ainda como um instrumento de inserção no mercado de trabalho. Essa formação não se restringe a ensinar um simples ofício ou uma profissão, mas fazer com que possam desenvolver atividades que relacionem grupos e pessoas, sociabilizando o conhecimento.

O projeto "Direito à memória das comunidades tradicionais: organização de acervo nos terreiros de candomblé" foi elaborado pela equipe da biblioteca com a equipe do Programa Territórios Negros e representantes de terreiros de candomblé.

Este relato de experiência não pretende mencionar conceitos para a expressão direito à memória. O projeto relatado aqui foi idealizado e executado em parceria por comunidades de terreiros e pela Koinonia. O termo foi sugerido por ambas as partes, por entenderem que, para as comunidades tradicionais, o direito à memória é um direito que caminha lado a lado com a conquista dos demais direitos.

As primeiras oficinas foram realizadas nos terreiros Dandalungua Cocuazenza e para o Ilê Axé Iyá Nassô Oká - Casa Branca, todos situados em Salvador, Bahia.

\section{Primeiros passos: Candomblé - bem- vindo ao desconhecido}

Fui educada por uma avó extremamente católica e, quando recebi a proposta deste trabalho, fiquei com um pouco de receio do que encontraria nessa viagem devido à educação cristã. Era a primeira vez que entraria em um terreiro de candomblé.

Essa viagem foi de grandes apresentações e constitui-se em minha primeira ida a Salvador, cujo povo é receptivo e encantador. No primeiro dia na cidade recebi um convite para almoçar no Terreiro da $\mathrm{Casa}^{3}$ Branca. Ele fica na periferia, no bairro Vasco da Gama, um dos mais antigos santuários brasileiros da religião de matriz africana e o primeiro terreiro a ser tombado como patrimônio histórico e etnográfico.

O momento que escolhemos para realização da oficina também constava no calendário festivo no terreiro. À noite, a Casa Branca seria um belo cenário para uma festa. Fui recepcionada pelo secretário executivo da Koinonia e também pelo ogã ${ }^{4}$ Rafael Oliveira, sacerdote da Casa Branca. O terreiro estava mais bonito sob a escuridão da noite, todo ornamentado, e quem entrasse saberia que ali aconteceria uma grande festa. Fui envolvida pelos atabaques, pela dança e pelos trajes, fiquei em êxtase por presenciar pessoas simples serem recebidas como deuses. Naquele momento respeitei o candomblé e vi que poderia começar, sem temor,

\footnotetext{
${ }^{3} \mathrm{O}$ significado de casa é sinônimo de terreiro de candomblé, ou seja, casa de candomblé. Livro Candomblé: diálogos fraternos contra a intolerância religiosa (SOARES, 2003, p.78).

4 Titulo da hierarquia masculina do candomblé, conferido a pessoas prestadoras de relevantes serviços à comunidade-terreiro ou mesmo a especialistas rituais, como músicos, sacrificadores de animais etc., ou ainda, a outras de status social ou financeiro elevado (LOPES, 2004, p.489).
} 
o trabalho proposto para a Casa Branca e para mais nove ${ }^{5}$ Terreiros de Candomblé.

\section{Resgatar para preservar}

Como já mencionei, os terreiros selecionados para a primeira atividade foram Ilê Axé Nassô Okâ - Casa Branca e Manso Dandalungua Cocuazenza, também um dos mais antigos de Salvador. Casas de nações ${ }^{6}$ e bairros distintos.

Os terreiros tiveram a oportunidade de selecionar participantes para oficina e também para dar continuidade à atividade. A curiosidade de manusear documentos sobre a religião e sobre a sua casa foi um fator determinante na motivação dos filhos e filhas desses terreiros, mas estipulamos que cada oficina teria no máximo três agentes.

\section{CONHECENDO O ACERVO}

O próximo passo era conhecer o acervo para definir a forma de trabalho. Os dois terreiros armazenavam o material em saletas, sem nenhum critério de organização. Todos os documentos estavam empoeirados. Os tipos de documentos encontrados foram livros, periódicos, fotografia (festas, familiares, visitantes e eventos do movimento), atas das associações, relatórios de atividades, depoimentos, receitas, $\mathrm{CDs}$ e fitas cassete.

O conteúdo dos documentos (bibliográfico ou/e arquivísitico) diferenciava conforme os critérios e as normas estabelecidas em cada terreiro. Quando se fala de fotografia, o Terreiro Casa Branca proíbe uso de máquina fotográfica e filmadora em festas, por isso não encontramos fotos de transes e rituais. Já em outras casas encontramos tais fotos com essa descrição. No acervo de ambas as casas encontra-se excelente material sobre a história do terreiro: atas, relatórios e depoimentos da época da fundação em

\footnotetext{
${ }^{5}$ De 2005 a 2009 Koinonia ministrou nove oficinas em terreiros de candomblé.

${ }^{6}$ Diagnóstico de diferenciação teológica de diferentes tipos de candomblé. As diferenças se constituíram a partir da hegemonia de uma matriz cultural africana, entre outras na história do terreiro. (SOARES, 2003, p.78).
}

Ci. Inf., Brasília, DF, v. 39 n. 2, p.84-91, maio/ago., 2010 suporte papel (datilografados ou manuscritos). Esses documentos foram guardados pela associação ou por uma pessoa mais velha da casa, normalmente a opção mais frequente.

A pretensão do projeto era de apresentar alguns mecanismos e normas básicas de organização de acervo, usando procedimentos de organização de acervo das áreas de biblioteconomia e arquivologia.

Com a produção e gestão da informação, as atividades têm uma possibilidade significativa de contribuir na melhoria da qualidade de vida social pelo acesso a estas informações, buscando meios, ideias, técnicas que auxiliem na construção e reconstrução da história de cada um.

\section{Como classificar?}

Precisei definir de forma simplificada os mecanismos de trabalho aos participantes. Os instrumentos para o trabalho foram os seguintes:

Livro de tombo: foi utilizado para registro e gerenciamento dos livros.

Catalogação: extraímos os dados registrados pela editora na folha de rosto de cada obra, tais como autor, título, edição, local, editor e data. Os dados foram descritos em fichas impressas.

Para as fotografias elaboramos fichas de formato e conteúdo diferenciado.

A Koinonia ficou responsável pela aquisição do material de consumo, como livro de tombo, etiquetas, borrachas, canetas esferográficas (azuis e vermelhas), clipes, cola, grampeadores, furadores de papel, lápis 6b, carimbos, almofadas para carimbo, caixas-arquivo, planilhas (50 cópias de cada ficha para classificação), réguas e manual descrevendo passo a passo como preencher as fichas de classificação.

Os dois terreiros receberam o kit para iniciar a tarefa e, em caso de término dos materiais, eles se comprometeram com a sua reposição. 


\section{AS OFICINAS DE DIREITO À MEMÓRIA}

A Koinonia acredita que a memória em si é um direito cultural a ser observado e, particularmente, as comunidades tradicionais valorizam essa dimensão de suas vidas. Para além da memória oral, há diferentes recursos de documentação e registros iconográficos da história desses grupos, que organizados tornam-se serviços comunitários e de interesse público.

Para as oficinas, os interessados em participar foram mulheres negras na faixa etária de 20 a 50 anos, no total de quatro: duas para cada terreiro e, em ambas as casas, as participantes possuíam o segundo grau completo.

Como introdução dispusemos um espaço para expor sobre profissões e profissionais que trabalham na área da informação. Foi inesperado, para as participantes, saber que os profissionais da informação têm vasto leque de possibilidades de trabalho.

Não tivemos dificuldade em conduzir a atividade. O documento que mais fomentou a curiosidade das participantes nas duas oficinas foi a identificação e classificação iconográfica. A possibilidade de manusear fotos de momentos importantes e, em determinados casos, decisivos da história do terreiro foi o que mais encantou.

\section{Griots $^{7}$ : As multiplicadoras divulgam o trabalho}

Após as oficinas as multiplicadoras apresentavam para suas respectivas casas o trabalho e de que forma os usuários poderiam ter acesso ao material. A divulgação era feita por meio de reuniões das associações, reuniões de terreiros de Salvador, em quadros de avisos, notícias em sites e boletins do movimento. A política que todas as casas impuseram é que o acervo só poderia ser manuseado por filhos e convidados previamente autorizados.

\footnotetext{
7 O "griot" em tradições orais de vários povos africanos é um dos símbolos representativos de todos os narradores, dos que contam contos, cantam décimas, sábios, avós, mães e todos os demais personagens cênicos ou não, que, em muitas sociedades, são depositários de histórias, de testemunhos ou de tradições que ele conta.
}

\section{O que era somente iniciativa gerou frutos}

Com essa iniciativa, a Koinonia recebeu convites para ministrar a oficina Direito à Memória nos Terreiros Ilê Axé Odé Tola e Ilê Axé Abassá de Ogum. Nestes dois locais o perfil das participantes eram mulheres jovens e negras; somente uma cursava pedagogia e as demais tinham o segundo grau completo.

Tivemos uma grata surpresa com a disposição voluntária das primeiras participantes das oficinas dos Terreiros Ilê Axé Nassô Okâ - Casa Branca, Manso Dandalungua Cocuazenza, Ilê Axé Odé Tola, e Ilê Axé Abassá de Ogum, que se dispuseram a ser multiplicadoras desse projeto. As voluntárias receberam "treinamento" da metodologia para oficinas e ministraram-nas nos terreiros São Roque, Kalé Bokum, Viva Deus Bisneto, Terreiro de Jauá, Ilê Axé Pondamin Bominfá, sendo que o último contou com 15 participantes, inclusive crianças.

Até o momento essas oficinas eram ministradas com material impresso e não contávamos com tecnologia digital para auxiliar no trabalho. Os terreiros São Roque e Terreiro de Jauá possuem computadores; então, propusemos trabalhar com sistemas de automação de biblioteca gratuitos. Os terreiros optaram pelo programa Minibiblio ${ }^{8}$, desenvolvido pela empresa Athenas Software e Systems.

\section{Manual de procedimentos}

Em 2007 o Núcleo de Documentação da Koinonia promoveu com o Programa Egbé Territórios uma publicação de referência: o Fala Egbé Direitos, no qual divulgamos o manual de registro e documentação, instrumento prático de trabalho para auxiliar os terreiros capacitados ou não. O conteúdo da obra mostra como identificar documentos (fotos, fichas e forma de cadastro), lista de consumo necessário para organização de acervos, lista de sistema de automação de bibliotecas e glossário de palavras importantes, como o que é autor, biblioteca etc.

\footnotetext{
${ }^{8}$ Caso queira conhecer os sistema. Acesse o site: http://www. athenas.com.br/
} 
Monitoramento das atividades: o que aconteceu após as oficinas?

Com nove terreiros atendidos pela Koinonia, tivemos a necessidade de retornar a essas casas e saber o que aconteceu posteriormente às oficinas.

Em 2008, a equipe do programa Egbé e as voluntárias retornaram para averiguar as planilhas de classificação e o livro de tombo. Foram constatados os seguintes dados:

Ilê Axé Casa Branca: oficina realizada em 2005. Forma de cadastro: manual (fichas impressas) Total de cadastro: 516 documentos

Tipos de documento: livros, periódicos, fotografia, atas, depoimentos, relatórios, receitas, CDs e fitas cassete.

Axé Abassá de Ogum: oficina realizada em 2006.

Forma de cadastro: manual (fichas impressas)

Total de cadastro: 250 documentos

Tipos de documento: livros, periódicos, fotografia, atas, relatórios, receitas, CDs e fitas cassete.

Observação: Faz parte do acervo toda a documentação e notícias de jornais e revistas sobre o caso Mãe Gilda. A revista Veja publicou matéria em 1992, em que aparecia uma foto de Mãe Gilda, trajada com roupas de sacerdotisa, tendo a seus pés uma oferenda como forma de solicitar aos orixás que atendessem às súplicas daquele momento. A Igreja Universal do Reino de Deus (Iurd) publicou essa fotografia no jornal Folha Universal, em outubro de 1999, associada a uma agressiva e comprometedora reportagem sobre charlatanismo, sob o título: "Macumbeiros charlatões lesam o bolso e a vida dos clientes". A matéria afirmava estar crescendo no país um "mercado de enganação". A publicação dessa foto marca o início de um doloroso, porém definidor processo de luta por justiça da família e de todos os religiosos do Candomblé. Diante destes fatos, com a saúde fragilizada, Mãe Gilda não suportou os ataques. Seu estado de saúde piorou e ela veio a falecer no dia 21 de janeiro de 2000.

Logo após o reconhecimento da agressão à Mãe Gilda, sua filha, Jaciara Ribeiro dos Santos, moveu

Ci. Inf., Brasília, DF, v. 39 n. 2, p.84-91, maio/ago., 2010 uma ação contra a Igreja Universal do Reino de Deus (Iurd), por danos morais e uso indevido da imagem. Procurados por Jaciara, os advogados da Koinonia (convênio com a Associação de Advogados de Trabalhadores Rurais no Estado da Bahia - AATR) passaram a representar a família na ação por meio da assessoria do Programa EgbéTerritórios Negros. O falecimento de Mãe Gilda deu-se no dia seguinte em que assinou a procuração, constituindo seus advogados para defender o caso, em clara expressão do seu desejo por reparação. O processo ainda está em fase de recurso.

Terreiro de Jauá: oficina realizada em 2007. Forma de cadastro: informatizada (minibiblio) Total de cadastro: 150 livros cadastrados Tipos de documento: livros, periódicos, fotografia, atas, relatórios, receitas, CDs e fitas cassete.

Manso Dandalungua Cocuazenza - oficina realizada em 2005.

Forma de cadastro: manual (fichas impressas)

Total de cadastro: 135 documentos

Tipos de documento: livros, periódicos, fotografia, atas, relatórios, CDs e fitas cassete.

Terreiro Tumba Junçara - oficina realizada em 2007. Forma de cadastro: manual (fichas impressas)

Total de cadastro: 200 documentos

Tipos de documento: livros, periódicos, fotografia, atas, relatórios, CDs e fitas cassetes.

Viva Deus Bisneto - oficina realizada em 2007.

Forma de cadastro: manual (fichas impressas)

Total de cadastro: 10 documentos

Tipos de documento: atas e relatórios.

Terreiro São Roque - Oficina realizada em 2007. Forma de cadastro: informatizada (minibiblio)

Total de cadastro: 1.650 documentos Tipos de documento: livros, periódicos, fotografia, atas, depoimentos, relatórios, receitas, CDs e fitas cassete.

Ilê Asé Kale Bokun - Oficina realizada em 2007. Forma de catalogação: manual (fichas impressas) Total cadastrado: 223 documentos 
Tipos de documento: livros, periódicos, fotografia, atas, depoimentos e relatórios.

Outras atividades geradas após as oficinas foram incentivo à leitura; procura por cursos de aprimoramento; solicitação de livros ao Ministério da Educação e Unesco; feira de livros e restauração de algumas fotos.

\section{CONCLUINDO E REFLETINDO SOBRE A AÇÃO}

Nosso foco principal não era ministrar oficinas para agentes de leitura - trabalho este que o Ministério do Desenvolvimento Agrário realiza no projeto Arca das Letras ${ }^{9}$, em que agrupa publicações por assunto - e sim, que os terreiros tivessem acesso a dados básicos para organização de acervos, que fossem autônomos e agregassem iniciativas para tal atividade.

As oficinas trouxeram benefícios à comunidade, permitiram acesso à documentação histórica, preservação, organização e disponibilização do seu acervo de forma impressa ou digital.

Nesse processo, a Koinonia fortaleceu um trabalho com pessoas que não tiveram contato com uma biblioteca ou espaço similar e conseguiu manter esse laço para atividades futuras na mesma área, fomentando métodos e procedimentos de como preservar e organizar a partir de uma discussão coletiva com as comunidades de terreiros.

Esse trabalho nos leva a acreditar, como profissionais da informação, que precisamos inserir em nossos discursos, em nossas listas de discussão e em nossos eventos, temas como saberes das comunidades tradicionais, etnoconhecimentos e afrocentricidade ${ }^{10}$,

\footnotetext{
9 O Arca das Letras foi criado em 2003 pela SRA/MDA para incentivar a leitura no meio rural, Desde o seu lançamento, já foram implantadas 4.329 bibliotecas. As comunidades escolhem os assuntos que formam os acervos, o local onde a biblioteca é instalada e indicam os moradores que serão capacitados como agentes de leitura

${ }^{10}$ Sobre o tema mencionado indico pela leitura o livro: Nascimento, Elisa Larkin (Org.). Afrocentricidade, 2009.
}

conceito cunhado e elaborado por Molefi Asante. Tal como mencionado por Miranda (2009), esses conhecimentos são transmitidos de geração a geração, de forma oral e/ou escrita, e algumas comunidades e profissionais consideram-nos secundários.

Historicamente nós, profissionais da informação, trabalhamos com a informação registrada. Precisamos abrir esse escopo teórico-prático, o que nos possibilitará novos espaços interdisciplinares dentro da ciência da informação.

Conforme Costa (2010), uma das mais cruéis formas de se apagar a autoestima de um povo é deixar que sua cultura se perca, que seus sítios históricos se deteriorem com as intempéries, que seus rituais religiosos sejam esquecidos.

Devemos avançar no sentido de definir políticas públicas que invistam em capacitação de recursos humanos e que reconheçam a importância da preservação da memória cultural afro-brasileira (COSTA, 2010, p. 4).

As comunidades de terreiros precisam ter o direito de participar como agentes nesse hiato ${ }^{11}$ e recolher o material relativo à memória de seus grupos. Isso é um direito de todos. Direito à informação e à memória.

Artigo submetido em 05/05/2009 e aceito em 15/02/2011.

${ }^{11}$ FREITAS, Lídia Silva; GOMES, Sandra Lúcia Rebel. Quem decide o que é memorável?: A memória de setores populares e os profissionais da informação. In: FORO SOCIAL DE INFORMAÇÃO, DOCUMENTAÇÃO, BIBLIOTECONOMIA. Buenos Aires, 26-28 ago. 2004. 11 p.

Ci. Inf., Brasília, DF, v. 39 n. 2, p.84-91, maio/ago., 2010 
Direito à memória das comunidades tradicionais: organização de acervo nos terreiros de candomblé de Salvador, Bahia

\section{REFERÊNCIAS}

BRASIL. Ministério do Desenvolvimento Agrário. Projeto Arca das letras. Disponível em: < http://www.mda.gov.br/portal/>. Acesso em: 23 abr. 2009.

COSTA, Hildete Santos Pita. Os gestores da informação, a educação plural e os acervos culturais afro-brasileiros. Revista África e Africanidades, Rio de Janeiro, ano 3, n.9, maio 2010. Disponível em: $<$ http://www.africaeafricanidades.com/documentos/Os_gestores_ da_informacao.pdf>. Acesso em: 8 fev. 2011.

FREITAS, Lídia Silva; GOMES, Sandra Lúcia Rebel. Quem decide o que é memorável?: A memória de setores populares e os profissionais da informação. In: FORO SOCIAL DE INFORMAÇÃO, DOCUMENTAÇÃO, BIBLIOTECONOMIA, Buenos Aires, 2004. Anais... Buenos Aires, 26-28 ago. 2004. 11 p.

Koinonia Presença Ecumênica e Serviço. Informativo Fala egbé direitos. v. 7, n.18, abr. 2009.
Programa Egbé. Disponível em: <www.koinonia.org.br>. Acesso em: 23 abr. 2009.

LOPES, Nei. Enciclopédia Brasileira da Diáspora Africana. São Paulo: Selo Negro, 2004.

MIRANDA, Marcos. Organização do etnoconhecimento: a representação do conhecimento afrodescendente em Religião na CDD. Revista África e Africanidades. Disponível em: < http:// www.africaeafricanidades.com/documentos/A_organizacao_do_ etnoconhecimento.pdf >. Acesso em: 23 abr. 2009.

OLIVEIRA, Rafael Soares (Org.). Candomblé: diálogos fraternos para superar a intolerância religiosa. Rio de Janeiro: KOINONIA Presença Ecumênica, 2007.

Feitiço de Oxum: Um estudo sobre o Ilê Axé Iyá Nassô Oká e suas relações em rede com outros terreiros. 2005. 383 f. Tese (Doutorado em Ciências Sociais)-Universidade Federal da Bahia, Salvador, 2005. 